\title{
Ledipasvir and Sofosbuvir for Acute Hepatitis C Virus Monoinfection Associated with a High Risk of Acute Liver Failure
}

\author{
Takeshi Hatanaka ${ }^{1,2}$, Atsushi Naganuma ${ }^{1}$, Yumeo Tateyama ${ }^{1}$, Fukiko Yoshinari ${ }^{1}$, \\ Takashi Hoshino ${ }^{1}$, Ken Sato ${ }^{3}$, Su Su Hmwe ${ }^{4}$, Hideki Aizaki ${ }^{4}$, Takaji Wakita ${ }^{4}$, \\ Satoru Kakizaki ${ }^{3}$ and Toshio Uraoka ${ }^{3}$
}

\begin{abstract}
:
A 72-year-old Japanese man was referred to our hospital with yellow discoloration of the sclera and liver dysfunction. He was diagnosed with acute hepatitis C virus (HCV) infection on the basis of HCV-RNA positivity and anti-HCV seroconversion. A transjugular liver biopsy confirmed submassive hepatic necrosis. Five days after admission, no flapping tremor was observed, and the prothrombin time-international normalized ratio (PT-INR) and total bilirubin level showed increases of 1.70 and $17.8 \mathrm{mg} / \mathrm{dL}$, respectively. The Model for End-Stage Liver Disease score was determined to be 25, and the risk of acute liver failure (ALF) was estimated to be $48 \%$ according to the Japan Hepatic Encephalopathy Prediction Model. Considering that rapid $\mathrm{HCV}$ clearance and temporary suppression of the immune response would prevent ALF, we prescribed oral ledipasvir (LDV) $90 \mathrm{mg}$ and sofosbuvir (SOF) $400 \mathrm{mg}$ for 12 weeks and intravenously injected methylprednisolone $1 \mathrm{~g}$ for 3 days. His PT-INR promptly improved, although the total bilirubin level increased to 30.3 $\mathrm{mg} / \mathrm{dL}$. Plasma bilirubin absorption was performed three times, and the total bilirubin level gradually decreased. HCV-RNA was still detectable at six weeks after the start of LDV/SOF therapy and finally undetectable at eight weeks. There were no adverse events associated with LDV/SOF. The patient was discharged 73 days after admission. A sustained virological response was achieved at 12 and 24 weeks after treatment. The findings from this case suggest that LDV/SOF therapy can be a promising option for acute HCV monoinfection associated with a high risk of ALF.
\end{abstract}

Key words: acute liver failure, hepatitis C, ledipasvir, sofosbuvir

(Intern Med 58: 2969-2975, 2019)

(DOI: 10.2169/internalmedicine.2982-19)

\section{Introduction}

Approximately 71 million individuals worldwide are affected by hepatitis $\mathrm{C}$ virus (HCV) infection, and the estimated global prevalence rate is $1.0 \%$ (1). Injection drug use and unsafe healthcare practices are well-known risk factors for HCV infection. Chronic hepatitis occurs in 54-86\% cases with acute $\mathrm{HCV}$ infection (2), and it can lead to cirrhosis and hepatocellular carcinoma.

Acute liver failure (ALF), defined as evidence of coagulopathy, usually with a prothrombin time-international normalized ratio $(\mathrm{PT}-\mathrm{INR}) \geq 1.5$, and any degree of an altered sensorium within 8 weeks of the first symptoms in the absence of prior liver disease (3), is considered a rare complication of acute $\mathrm{HCV}$ infection (4-6), although reports are controversial. To our knowledge, only a few cases of ALF due to HCV have been reported to date $(7,8)$.

\footnotetext{
${ }^{1}$ Department of Gastroenterology, National Hospital Organization Takasaki General Medical Center, Japan, ${ }^{2}$ Department of Gastroenterology, Gunma Saiseikai Maebashi Hospital, Japan, ${ }^{3}$ Department of Gastroenterology and Hepatology, Gunma University Graduate School of Medicine, Japan and ${ }^{4}$ Department of Virology II, National Institute of Infectious Diseases, Japan

Received: March 6, 2019; Accepted: April 21, 2019; Advance Publication by J-STAGE: June 27, 2019

Correspondence to Dr. Takeshi Hatanaka, hatanaka@qk9.so-net.ne.jp
} 
Direct-acting antiviral (DAA) therapy has been proven to be safe and effective for managing chronic $\mathrm{HCV}$ infection $(9,10)$; however, its role in the management of acute infection remains unclear. Furthermore, little is known about the safety and efficacy of DAA for severe acute HCV infection associated with a high risk of ALF.

We herein report a rare case involving an elderly Japanese man with acute HCV monoinfection associated with a high risk of ALF who was successfully treated with ledipasvir (LDV) and sofosbuvir (SOF) therapy.

\section{Case Report}

A 72-year-old Japanese man with yellow discoloration of the sclera and epigastrium for 7 and 4 days, respectively, and liver dysfunction was referred to Takasaki General Medical Center for an evaluation. He was not taking any medication other than famotidine and teprenone that had been prescribed by a local clinic two days before admission. He had no history of underlying liver diseases, alcohol abuse, blood transfusion, illicit or illegal intravenous drug use, or sexual contact with a hepatitis carrier in the previous six months. He had received 18 hyaluronic acid injections for right knee osteoarthritis over the last 6 months at another local clinic.

Our physical examination revealed mild conjunctival jaundice and tenderness over the epigastrium. No degree of an altered sensorium, including flapping tremor, was observed. Laboratory data on admission were as follows: PT-INR, 1.54; total bilirubin, $4.6 \mathrm{mg} / \mathrm{dL}$; aspartate aminotransferase, 3,111 IU/L; and alanine aminotransferase (ALT), 3,857 IU/ L. A third-generation enzyme-linked immunosorbent assay (ARCHITECT, Abbott Japan, Chiba, Japan) revealed antiHCV positivity, although a test performed 4 years earlier had shown negativity. The anti-HCV titer was 4.27 (cut-off: 1.00), which increased to 10.1 at 2 weeks after admission. HCV-RNA was detected by reverse transcription polymerase chain reaction (COBAS TaqMan HCV assay, Version 2.0; Roche Molecular Diagnostics, Tokyo, Japan). The HCV genotype was 1b, and the interleukin-28B (IL28B) genotype (rs8099917) was T/T. Serological screening for the other hepatitis viruses, including IgM-hepatitis A virus (HAV), IgG-HAV, hepatitis B virus (HBV) markers (hepatitis B antigen, hepatitis B surface antibody, hepatitis B core antibody, HBV-DNA), and IgA-hepatitis E virus, showed negative findings, while that for Epstein-Barr virus and cytomegalovirus showed an infection history. A human immunodeficiency virus (HIV) antibody test showed negative findings (Table 1).

Because of coagulopathy, we performed a transjugular liver biopsy (TJLB) instead of a percutaneous liver biopsy under ultrasound guidance three days after admission (11). The liver specimen showed extensive neutrophilic and lymphocytic infiltration with regeneration, which indicated submassive hepatic necrosis (Fig. 1). Five days after admission, an altered sensorium, including flapping tremor, was still not observed, and his PT-INR and total bilirubin level showed increases of 1.70 and $17.8 \mathrm{mg} / \mathrm{dL}$, respectively. The Model for End-Stage Liver Disease (MELD) (12) score was determined to be 25 , and the risk of ALF was estimated to be $48 \%$ according to the Japan Hepatic Encephalopathy Prediction Model (JHEPM) (13).

Following institutional review board approval (approval number: H30-81) and the acquisition of informed consent from the patient, we initiated oral treatment with the NS5A inhibitor LDV (90 mg) and NS5B inhibitor SOF (400 mg; Harvoni, Gilead Sciences, Tokyo, Japan) for 12 weeks. We also administered intravenous methylprednisolone $1 \mathrm{~g}$ for 3 days. His PT-INR promptly improved to 1.41 after 4 days of combination therapy LDV/SOF with methylprednisolone. Because the total serum bilirubin level increased to $30.3 \mathrm{mg} /$ $\mathrm{dL}$, plasma bilirubin absorption was performed three times. Consequently, the total bilirubin level gradually decreased. HCV-RNA levels were 6.2, 4.4, 3.4, 2.1 , and <1.2 $\log _{10} \mathrm{IU} /$ $\mathrm{mL}$ at baseline and 1, 2, 4, and 6 weeks after the start of LDV/SOF therapy, respectively, and they were undetectable at 8 weeks. There were no adverse events associated with LDV/SOF therapy, and the patient was discharged at 73 days after admission.

A sustained virological response (SVR) was achieved at 12 (SVR 12) and 24 (SVR 24) weeks after treatment. The clinical course and HCV-RNA levels are shown in Fig. 2. The full genomic sequence of an HCV isolate (KT4-Gt1b) recovered from the patient was determined according to previously described methods $(14,15)$ and deposited in the DDBJ/EMBL/GenBank databases under the accession number LC462122. There were no nonstructural protein (NS) 5A resistance-associated substitutions (RASs).

\section{Discussion}

To our knowledge, this was the first case of severe acute hepatitis $\mathrm{C}$ monoinfection treated with DAA therapy for the prevention of ALF. We diagnosed acute HCV infection based on HCV-RNA positivity, anti-HCV seroconversion, and an ALT level of $>20$ times the upper limit of normal (16). Our diagnosis was also supported by the increased anti-HCV antibody level at 2 weeks after admission and the negative screening test findings for other liver diseases. Repeated hyaluronic acid injections for osteoarthritis treatment were suspected to be the cause of HCV transmission. The MELD score is recommended as a prognostic scoring system for patients with acute liver disease (17). In the present case, the MELD score was determined to be 25, and the risk of ALF was estimated to be $48 \%$ according to JHEPM (13). Accordingly, we prescribed oral LDV/SOF therapy for 12 weeks and intravenously injected methylprednisolone $1 \mathrm{~g}$ for 3 days, believing that rapid $\mathrm{HCV}$ clearance and temporary suppression of the immune response would prevent ALF development. There were no treatment-related adverse events, and the patient was discharged 73 days after admission.

A previous study documented spontaneous remission in 
Table 1. Laboratory Data.

\begin{tabular}{lclc}
\hline \multicolumn{1}{c}{ Variable } & Results & \multicolumn{1}{c}{ Variable } & Results \\
\hline WBC & $64 \times 10^{2} / \mathrm{mm}^{3}$ & CRP & $0.56 \mathrm{mg} / \mathrm{dL}$ \\
Neutrophil & $55.0 \%$ & NH3 & $64 \mu \mathrm{g} / \mathrm{dL}$ \\
Eosinophil & $3.0 \%$ & TSH & $3.51 \mu \mathrm{IU} / \mathrm{mL}$ \\
Basophil & $1.0 \%$ & Free T3 & $2.39 \mathrm{pg} / \mathrm{mL}$ \\
Monocytes & $8.0 \%$ & Free T4 & $1.17 \mathrm{ng} / \mathrm{dL}$ \\
Lymphocytes & $33.0 \%$ & IgG & $1,066 \mathrm{mg} / \mathrm{dL}$ \\
RBC & $495 \times 10^{4} / \mathrm{mm}^{3}$ & IgA & $297 \mathrm{mg} / \mathrm{dL}$ \\
Hemoglobin & $15.3 \mathrm{~g} / \mathrm{dL}$ & IgM & $171 \mathrm{mg} / \mathrm{dL}$ \\
Platelet & $16.5 \times 10^{4} / \mathrm{mm}^{3}$ & ANA & $<40$ Times \\
PT & $42 \%$ & AMA-M2 & $<20$ Times \\
PT-INR & 1.54 & IgM-HAV antibody & Negative \\
APTT & $41.5 \mathrm{sec}$ & IgG-HAV antibody & Negative \\
Total protein & $6.7 \mathrm{~g} / \mathrm{dL}$ & Hepatitis B surface antigen & Negative \\
Albumin & $4.2 \mathrm{~g} / \mathrm{dL}$ & Hepatitis B surface antibody & Negative \\
T. bil. & $4.6 \mathrm{mg} / \mathrm{dL}$ & Hepatitis B core antibody & Negative \\
AST & $3,111 \mathrm{IU} / \mathrm{L}$ & HBV-DNA & Negative \\
ALT & $3,857 \mathrm{IU} / \mathrm{L}$ & Hepatitis C antibody & $4.26 \mathrm{COI}$ \\
LDH & $1,883 \mathrm{IU} / \mathrm{L}$ & HCV-RNA & 6.9 log $10 \mathrm{IU} / \mathrm{mL}$ \\
ALP & $642 \mathrm{IU} / \mathrm{L}$ & Genotype of HCV & $1 \mathrm{~b}$ \\
$\gamma$-GTP & $263 \mathrm{IU} / \mathrm{L}$ & NS5A RASs & None \\
ChE & $308 \mathrm{IU} / \mathrm{L}$ & IL28B (rs8099917) & T/T \\
BUN & $20 \mathrm{mg} / \mathrm{dL}$ & IgA-HEV antibody & Negative \\
Creatinine & $1.15 \mathrm{mg} / \mathrm{dL}$ & IgM-EBV VCA & Negative \\
eGFR & $51.2 \mathrm{~mL} / \mathrm{min}$ & IgG-EBV VCA & Positive \\
Blood glucose & $163 \mathrm{mg} / \mathrm{dL}$ & IgG-EBV EBNA & Positive \\
Sodium & $137 \mathrm{mEq/L}$ & IgM-CMV & Negative \\
Potassium & $4.4 \mathrm{mEq/L}$ & IgG-CMV & Positive \\
Chloride & $107 \mathrm{mEq/L}$ & & \\
\hline AIT:a & & \\
\hline
\end{tabular}

ALT: alanine aminotransferase, ALP: alkaline phosphatase, AMA: anti-mitochondrial antibody, ANA: anti-nuclear antibody, APTT: activated partial thromboplastin time, AST: aspartate aminotransferase, BUN: blood urea nitrogen, CMV: cytomegalovirus, CRP: C-reactive protein, EBV: Epstein-Barr virus, EBNA: Epstein-Barr virus nuclear antigen, eGFR: estimated glomerular filtration rate, HAV: hepatitis A virus, HBV: hepatitis B virus, HCV: hepatitis C virus, HEV: hepatitis E virus, IL28B: interleukin-28B genotype, LDH: lactate dehydrogenase, PT: prothrombin time, PT-INR: prothrombin timeinternational normalized ratio, RASs: resistance-associated substitutions, RBC: red blood cell, $\gamma$-GTP: gamma-glutamyltransferase, T. bil.: total bilirubin, TSH: thyroid stimulating hormone, VCA: virus capsid antigen, WBC: white blood cell
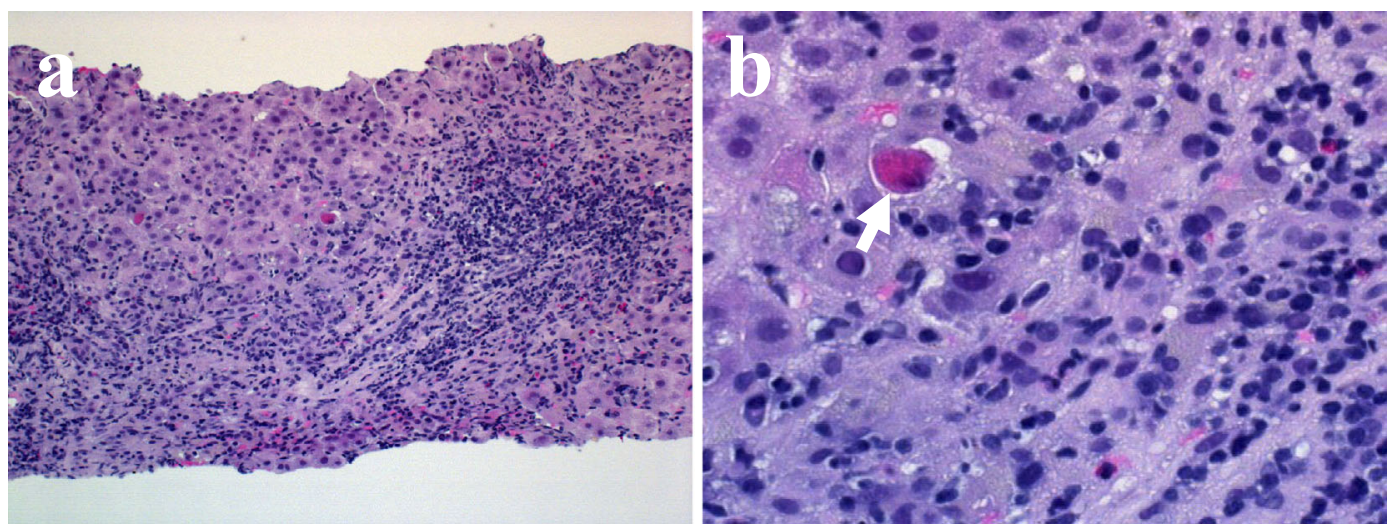

Figure 1. Microscopic findings for a liver specimen obtained from a 72-year-old Japanese man with acute severe hepatitis $\mathrm{C}$ virus monoinfection associated with a high risk of acute liver failure. (a) $\mathrm{A}$ histopathological analysis shows extensive neutrophilic and lymphocytic infiltration with regeneration, which indicates submassive hepatic necrosis. (b) A councilman body is also seen (white arrow). 


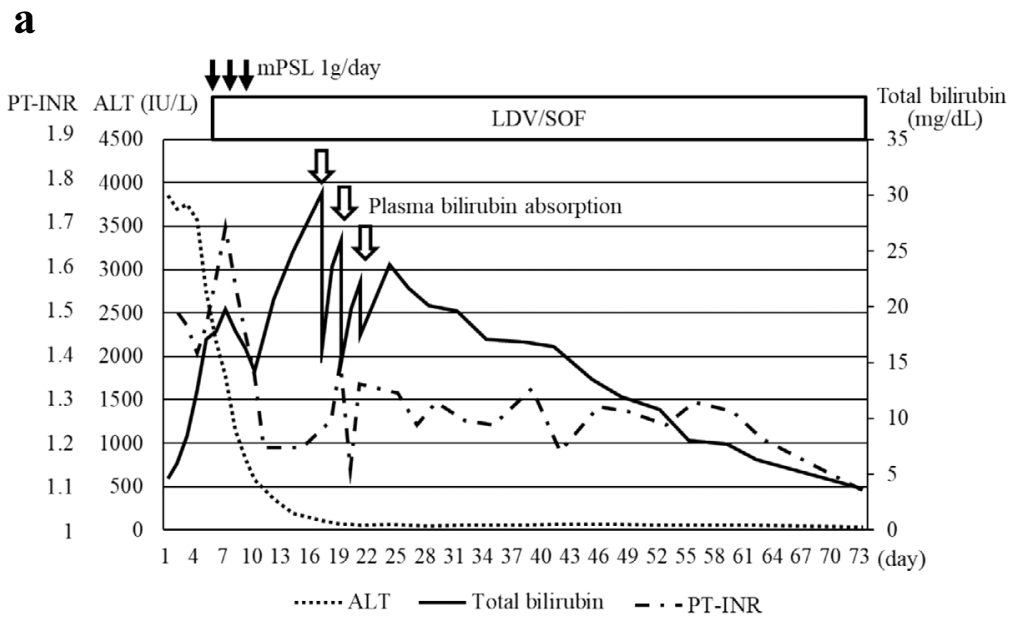

b

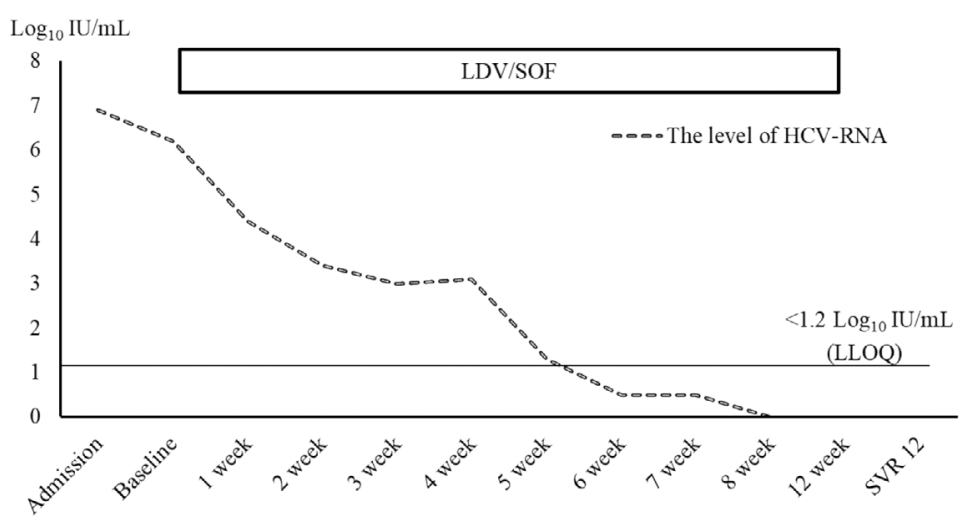

Figure 2. Clinical course and changes in hepatitis C virus (HCV) RNA levels in a 72-year-old man with acute severe hepatitis $\mathrm{C}$ virus monoinfection associated with a high risk of acute liver failure. (a) The prothrombin time-international normalized ratio (PT-INR) and total bilirubin level showed increase of 1.70 and $17.8 \mathrm{mg} / \mathrm{dL}$, respectively, 5 days after admission. This indicated a high risk of acute liver failure. Combination therapy with ledipasvir (LDV) $90 \mathrm{mg}$ and sofosbuvir (SOF) $400 \mathrm{mg}$ was administered for 12 weeks, with intravenous injection of methylprednisolone (mPSL) $1 \mathrm{~g}$ for 3 days. This improved the PT-INR, but the total bilirubin level increased to $30.3 \mathrm{mg} / \mathrm{dL}$. Plasma bilirubin absorption was performed three times, with a gradual decrease in the total bilirubin level. (b) The HCV-RNA levels were 6.2, 4.4, 3.4, 2.1, and $<1.2 \log _{10} \mathrm{IU} / \mathrm{mL}$ at baseline and $1,2,4$, and 6 weeks, respectively, and they were undetectable at 8 weeks after initial LDV/SOF treatment. ALT: alanine aminotransferase, LLOQ: lower limit of quantification

approximately $25 \%$ of patients with acute HCV monoinfection (18). Potential favorable factors for spontaneous $\mathrm{HCV}$ clearance include female sex $(19,20)$, symptomatic disease $(19,21)$, the absence of HIV coinfection $(22,23)$, the IL28B CC genotype $(20,21,24)$, and the HCV genotype $1(20,25)$. However, these factors have not been fully verified. During the period of interferon-based regimens, the rate of SVR was higher and its duration shorter in cases of acute hepatitis $\mathrm{C}$ than in those of chronic hepatitis $\mathrm{C}$.

At present, DAA is the established treatment for patients with chronic $\mathrm{HCV}$ infection because of its superior efficacy and safety $(9,10)$. However, the efficacy and safety of DAA therapy for acute $\mathrm{HCV}$ infection remain unclear. Successful eradication of $\mathrm{HCV}$ infection has several health benefits, including alleviation of liver inflammation, regression of liver fibrosis, and a reduction in the risk of hepatocellular carcinoma $(9,10)$. However, according to the latest European Association for the Study of the Liver guidelines (10), acute $\mathrm{HCV}$ infection should be treated with DAA therapy in order to prevent a transition to chronicity. Previous studies (26-28) have shown that the SVR 12 rate after SOF and ribavirin (RBV) therapy for acute or recent $\mathrm{HCV}$ monoinfection or HCV/HIV coinfection was 32-92\%. Other studies (29-32) evaluating acute $\mathrm{HCV}$ infection treated with $\mathrm{LDV} / \mathrm{SOF}$ for 4-12 weeks have reported an SVR 12 rate of $77-100 \%$ (Table 2). Of note, serious drug-related adverse events were not observed in these previous studies (26-32). In those studies, HCV-RNA was undetectable at 4 weeks in $70-100 \%$ patients (29-32), while it was undetectable at 2 weeks in approximately $80 \%$ patients and at 4 weeks in all patients in 


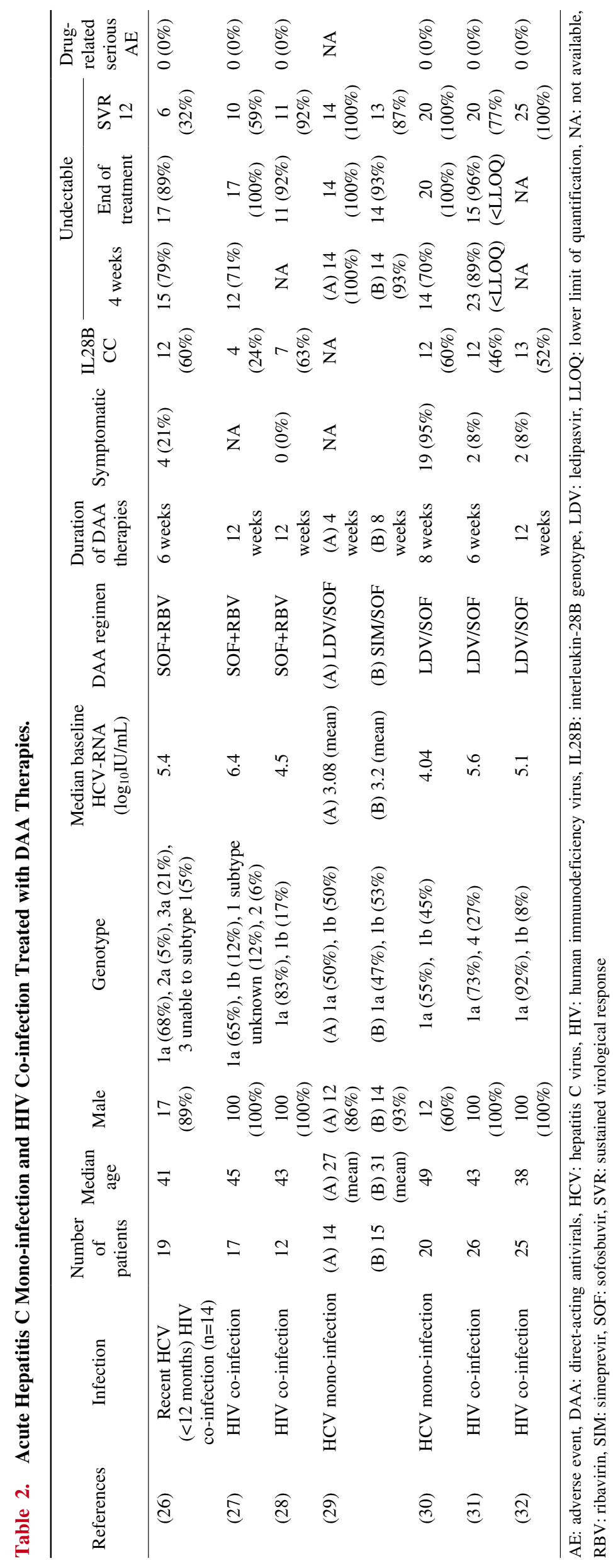


phase III clinical trials evaluating chronic $\mathrm{HCV}$ infection treated with $\operatorname{LDV} / \mathrm{SOF}(33,34)$. The optimal DAA regimen and duration of DAA therapy for acute HCV infection failed to be clarified by these studies.

We prescribed LDV/SOF therapy to our patient in order to alleviate the liver inflammation and prevent ALF, not to achieve SVR 12 and prevent progression to chronicity. We chose the LDV/SOF regimen because LDV/SOF, and not $\mathrm{SOF} / \mathrm{RBV}$, is available for $\mathrm{HCV}$ genotype 1 treatment in Japan. In addition, protease inhibitor regimens, including glecaprevir/pibrentasvir and grazoprevir/elbasvir, are contraindicated for patients with decompensated cirrhosis (Child-Pugh class B or class C) (10). We therefore considered LDV/SOF to be a safer regimen for acute hepatitis $\mathrm{C}$ patients with severe jaundice than protease regimens. We selected a duration of 12 weeks because HCV-RNA was detectable at 6 weeks and completely undetectable at 8 weeks after therapy initiation. The IL28B genotype in our case was T/T (rs8099917), and there were no NS5A RASs. Accordingly, we expected that $\mathrm{HCV}$ would be rapidly cleared by the patient's immune system and antiviral agents. The reason for this prolonged viremia remains uncertain. In addition, we had to carefully consider whether or not the prescription of DAA would be beneficial, as patients with severe acute infection and a high risk of ALF, such as the present patient, were not included in the previous reference studies.

In the present case, we performed a TJLB in order to obtain not only an accurate liver diagnosis but also to determine the degree of liver necrosis, resulting in a diagnosis of submassive hepatic necrosis. The presumptive diagnosis was changed in about $18 \%$ of ALF patients after a liver biopsy, according to previous reports $(35,36)$. In addition, the degree of liver necrosis determined by a histological liver specimen may help predict the prognosis in ALF patients $(35,36)$. A routine liver biopsy is not recommended because the risk of such a procedure is higher in patients with coagulopathy than in those without it (17). Accordingly, caution must be practiced until whether or not the benefit of a liver biopsy outweighs its risk in ALF patients is determined.

Although the efficacy of steroid therapy to ALF patients remains unknown (37-40), a previous study suggested that steroid therapy might be effective in patients with acute liver injury before the development of ALF (41). This study showed that a $40 \%$ JHEPM probability, PT-INR of 1.53 , and PT of 52\% constituted appropriate timing of steroid therapy in order to prevent the development of ALF (41). It also showed that the PT after four days of steroid therapy was a useful marker for predicting the development of ALF (41). In the present patient, we administered intravenous methylprednisolone $1 \mathrm{~g}$ for 3 days when his JHEPM probability and PT-INR were $48 \%$ and 1.70 , respectively, suggesting that we used steroid therapy at the appropriate timing; and indeed, his PT-INR was improved after 4 days of steroid therapy. The temporary suppression of the immune response by steroid therapy may also play an important role in pre- venting the development of ALF. A further study of the efficacy and the appropriate timing of steroid therapy should be conducted.

In conclusion, the findings from the present case suggest that LDV/SOF therapy may be a promising modality for severe acute $\mathrm{HCV}$ monoinfection associated with a high risk of ALF.

\section{Author's disclosure of potential Conflicts of Interest (COI).}

Ken Sato: Honoraria, AbbVie; Research funding, AbbVie. Satoru Kakizaki: Honoraria, Gilead Sciences; Research funding, Gilead Sciences and Bristol-Myers Squibb.

\section{Acknowledgement}

We are grateful to Dr. Nobuyuki Kato for the helpful discussions.

\section{References}

1. Polaris Observatory HCV Collaborators. Global prevalence and genotype distribution of hepatitis $C$ virus infection in 2015: a modelling study. Lancet Gastroenterol Hepatol 2: 161-176, 2017.

2. Seeff LB. Natural history of chronic hepatitis C. Hepatology 36: S35-S46, 2002.

3. Trey C, Davidson CS. The management of fulminant hepatic failure. Prog Liver Dis 3: 282-298, 1970.

4. Ostapowicz G, Fontana RJ, Schiodt FV, et al. Results of a prospective study of acute liver failure at 17 tertiary care centers in the United States. Ann Intern Med 137: 947-954, 2002.

5. Schiodt FV, Davern TJ, Shakil AO, McGuire B, Samuel G, Lee WM. Viral hepatitis-related acute liver failure. Am J Gastroenterol 98: 448-453, 2003.

6. Polson J, Lee WM. AASLD position paper: the management of acute liver failure. Hepatology 41: 1179-1197, 2005.

7. Inokuchi K, Nakata K, Hamasaki K, et al. Prevalence of hepatitis $\mathrm{B}$ or $\mathrm{C}$ virus infection in patients with fulminant viral hepatitis. An analysis using polymerase chain reaction. J Hepatol 24: 258264, 1996.

8. Kato T, Furusaka A, Miyamoto M, et al. Sequence analysis of hepatitis $\mathrm{C}$ virus isolated from a fulminant hepatitis patient. J Med Virol 64: 334-339, 2001.

9. AASLD/IDSA HCV Guidance Panel. Hepatitis C guidance: AASLD-IDSA recommendations for testing, managing, and treating adults infected with hepatitis C virus. Hepatology 62: 932-954, 2015.

10. European Association for the Study of the Liver. EASL recommendations on treatment of hepatitis C 2018. J Hepatol 69: 461$511,2018$.

11. Kalambokis G, Manousou $P$, Vibhakorn $S$, et al. Transjugular liver biopsy-indications, adequacy, quality of specimens, and complications-a systematic review. J Hepatol 47: 284-294, 2007.

12. Wiesner R, Edwards E, Freeman R, et al. Model for end-stage liver disease (MELD) and allocation of donor livers. Gastroenterology 124: 91-96, 2003.

13. Takikawa Y, Endo R, Suzuki K, Tsubouchi H. Early prediction of short-term development of hepatic encephalopathy in patients with acute liver disease unrelated to paracetamol. A prospective study in Japan. J Hepatol 51: 1021-1029, 2009.

14. Wakita T. Isolation of JFH-1 strain and development of an $\mathrm{HCV}$ infection system. Methods Mol Biol 510: 305-327, 2009.

15. Date T, Morikawa K, Tanaka Y, et al. Replication and infectivity of a novel genotype $1 \mathrm{~b}$ hepatitis $\mathrm{C}$ virus clone. Microbiol Immunol 56: 308-317, 2012.

16. Santantonio T, Wiegand J, Gerlach JT. Acute hepatitis C: current 
status and remaining challenges. J Hepatol 49: 625-633, 2008.

17. Flamm SL, Yang YX, Singh S, Falck-Ytter YT. American Gastroenterological Association Institute Guidelines for the diagnosis and management of acute liver failure. Gastroenterology 152: 644-647, 2017.

18. Micallef JM, Kaldor JM, Dore GJ. Spontaneous viral clearance following acute hepatitis $\mathrm{C}$ infection: a systematic review of longitudinal studies. J Viral Hepat 13: 34-41, 2006.

19. Wang CC, Krantz E, Klarquist J, et al. Acute hepatitis C in a contemporary US cohort: modes of acquisition and factors influencing viral clearance. J Infect Dis 196: 1474-1482, 2007.

20. Grebely J, Page K, Sacks-Davis R, et al. The effects of female sex, viral genotype, and IL28B genotype on spontaneous clearance of acute hepatitis C virus infection. Hepatology 59: 109-120, 2014.

21. Tillmann HL, Thompson AJ, Patel K, et al. A polymorphism near IL28B is associated with spontaneous clearance of acute hepatitis $\mathrm{C}$ virus and jaundice. Gastroenterology 139: 1586-1592, 1592.e 1581, 2010.

22. Thomson EC, Fleming VM, Main J, et al. Predicting spontaneous clearance of acute hepatitis $\mathrm{C}$ virus in a large cohort of HIV-1infected men. Gut 60: 837-845, 2011.

23. Thomas DL, Astemborski J, Rai RM, et al. The natural history of hepatitis C virus infection: host, viral, and environmental factors. Jama 284: 450-456, 2000.

24. Rao HY, Sun DG, Jiang D, et al. IL28B genetic variants and gender are associated with spontaneous clearance of hepatitis $\mathrm{C}$ virus infection. J Viral Hepat 19: 173-181, 2012.

25. Harris HE, Eldridge KP, Harbour $S$, Alexander G, Teo CG, Ramsay ME. Does the clinical outcome of hepatitis $\mathrm{C}$ infection vary with the infecting hepatitis $\mathrm{C}$ virus type? J Viral Hepat $\mathbf{1 4}$ 213-220, 2007.

26. Martinello M, Gane E, Hellard M, et al. Sofosbuvir and ribavirin for 6 weeks is not effective among people with recent hepatitis C virus infection: the DARE-C II study. Hepatology 64: 1911-1921, 2016.

27. Naggie S, Marks KM, Hughes M, et al. Sofosbuvir plus ribavirin without interferon for rreatment of acute hepatitis $\mathrm{C}$ virus infection in HIV-1-infected individuals: SWIFT-C. Clin Infect Dis 64: 10351042, 2017

28. El Sayed A, Barbati ZR, Turner SS, et al. Sofosbuvir in the treatment of early HCV infection in HIV-infected men. HIV Clin Trials 18: 60-66, 2017.

29. Basu PP, Shah NJ, Aloysius MM, Kavali L, Shehi E, Brown RS Jr. Sofosbuvir and ledipasvir versus sofosbuvir and simeprevir combination therapy in the management of acute hepatitis $\mathrm{C}$ : a randomized open label prospective clinical pilot study. Slam C Study. J Hepatol 64: S806, 2016.
30. Deterding K, Spinner CD, Schott E, et al. Ledipasvir plus sofosbuvir fixed-dose combination for 6 weeks in patients with acute hepatitis $\mathrm{C}$ virus genotype 1 monoinfection (HepNet Acute HCV IV): an open-label, single-arm, phase 2 study. Lancet Infect Dis 17: 215-222, 2017.

31. Rockstroh JK, Bhagani S, Hyland RH, et al. Ledipasvir-sofosbuvir for 6 weeks to treat acute hepatitis $\mathrm{C}$ virus genotype 1 or 4 infection in patients with HIV coinfection: an open-label, single-arm trial. Lancet Gastroenterol Hepatol 2: 347-353, 2017.

32. Palaniswami PM, El Sayed A, Asriel B, Carollo JR, Fierer DS. Ledipasvir and sofosbuvir in the treatment of early hepatitis C virus infection in HIV-infected men. Open Forum Infect Dis 5: ofy 238, 2018.

33. Afdhal N, Zeuzem S, Kwo P, et al. Ledipasvir and sofosbuvir for untreated HCV genotype 1 infection. N Engl J Med 370: 18891898, 2014.

34. Kowdley KV, Gordon SC, Reddy KR, et al. Ledipasvir and sofosbuvir for 8 or 12 weeks for chronic HCV without cirrhosis. N Engl J Med 370: 1879-1888, 2014.

35. Donaldson BW, Gopinath R, Wanless IR, et al. The role of transjugular liver biopsy in fulminant liver failure: relation to other prognostic indicators. Hepatology 18: 1370-1376, 1993.

36. Singhal A, Vadlamudi S, Stokes K, et al. Liver histology as predictor of outcome in patients with acute liver failure. Transpl Int 25: 658-662, 2012.

37. Ware AJ, Jones RE, Shorey JW, Combes B. A controlled trial of steroid therapy in massive hepatic necrosis. Am J Gastroenterol 62: 130-133, 1974.

38. Gregory PB, Knauer CM, Kempson RL, Miller R. Steroid therapy in severe viral hepatitis. A double-blind, randomized trial of methyl-prednisolone versus placebo. N Engl J Med 294: 681-687, 1976.

39. Karkhanis J, Verna EC, Chang MS, et al. Steroid use in acute liver failure. Hepatology 59: 612-621, 2014.

40. Redeker AG, Schweitzer IL, Yamahiro HS. Letter: randomization of corticosteroid therapy in fulminant hepatitis. N Engl J Med 294: 728-729, 1976.

41. Kakisaka K, Kataoka K, Suzuki Y, Kuroda H, Takikawa Y. Appropriate timing to start and optimal response evaluation of high-dose corticosteroid therapy for patients with acute liver failure. J Gastroenterol 52: 977-985, 2017.

The Internal Medicine is an Open Access journal distributed under the Creative Commons Attribution-NonCommercial-NoDerivatives 4.0 International License. To view the details of this license, please visit (https://creativecommons.org/licenses/ by-nc-nd/4.0/).

(C) 2019 The Japanese Society of Internal Medicine Intern Med 58: 2969-2975, 2019 